\title{
MODELING OF COLD PLASTIC DEFORMATION OF THE HOLES MADE IN SPECIMENS OF SHAPE-MEMORY ALLOY
}

\author{
P. V. Yasnii, ${ }^{1}$ O. V. Dyvdyk, ${ }^{1,2}$ and V.P. Iasnii ${ }^{1}$
}

\begin{abstract}
The process of cold plastic deformation of a hole in a plate made of shape-memory alloy is simulated by the finite-element method by setting the mechanical characteristics and the temperatures of the onset and termination of direct and reverse phase transformations. By using the ANSYS Workbench software, we determine the distribution of residual stresses in the plate in the vicinity of a functional hole. The highest normal compressive and tensile stresses are formed in the middle part of the plate and at a distance of $2-4 \mathrm{~mm}$ from the edge of the hole, respectively.
\end{abstract}

Keywords: shape-memory effect, NiTi alloy, phase transformations, martensite, austenite, normal stresses, strengthening of the holes.

\section{Introduction}

The development of contemporary engineering advances new elevated requirements to structural materials and their characteristics of strength and durability. The shape-memory alloys (SMA) [1-3] have good characteristics of durability, high strength, high damping ability, and high resistance to the action of corrosive media [4, 5], which explains their extensive application in various branches of engineering. At low temperatures, in the absence stresses, martensite stays in the twin phase. Under mechanical loads, it passes into the reorientation phase and changes its microstructure [6].

The distributions of residual stresses in structural elements with holes after their cold pressure treatment can be found by using analytic [7], numerical [8-10], and experimental methods [8, 11]. The main regularities of the influence of mandrelling tension (degree of cold expansion) and the diameter of the hole on the distribution of stresses in the vicinity of the hole and the durability of plates made of aluminum alloys under loading with constant amplitude were established in $[10,12,13]$. The holes can be strengthened as a result of cold plastic deformation performed by using various technological procedures: punching of the balls or mandrels of conic shape with calibrating sections [13-15] and the methods of split bush [16, 17] or barrier drafting.

A method of cold hardening of the holes with the help of tools made of shape-memory alloys proves to be quite promising [18, 19]. In particular, we can mention an improved method of strengthening of the holes guaranteeing the formation of residual compressive stresses around the hole in the axial and radial directions [19] due to the application of tools with cylindrical collars made of shape-memory alloys. As usual, the shapememory effect is simulated by using the finite-element method (FEM) with the help of 3D thermomechanical models [20-22].

\footnotetext{
${ }^{1}$ I. Pulyui Ternopil National Technical University, Ternopil, Ukraine.

2 Corresponding author; e-mail: sashadyvdyk@gmail.com.
}

Translated from Fizyko-Khimichna Mekhanika Materialiv, Vol. 56, No. 2, pp. 46-51, March-April, 2020. Original article submitted December 13, 2019. 


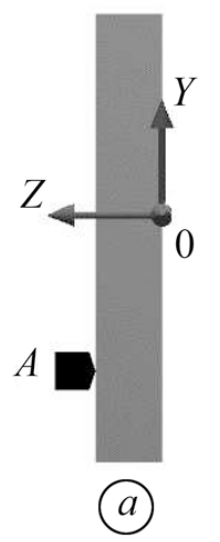

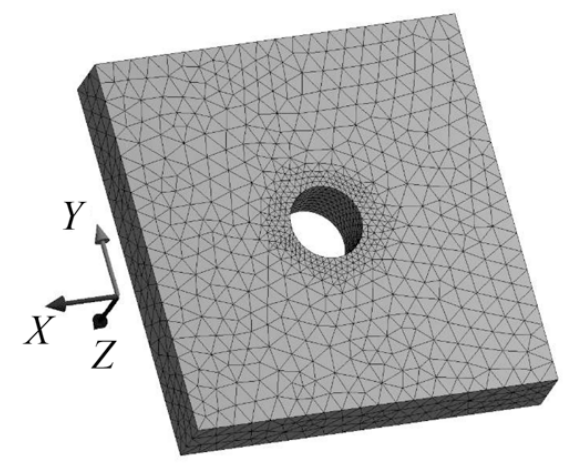

(b)

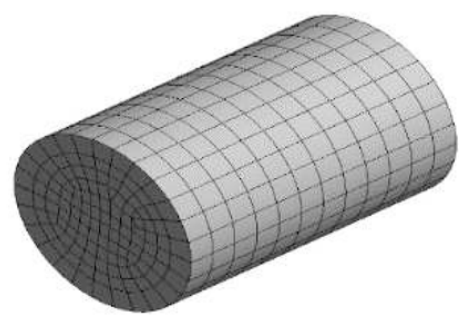

(c)

Fig. 1. Plate in the $X Y Z$ coordinate system (a), 3D finite-element model of the plate (b), and the working tool (c).

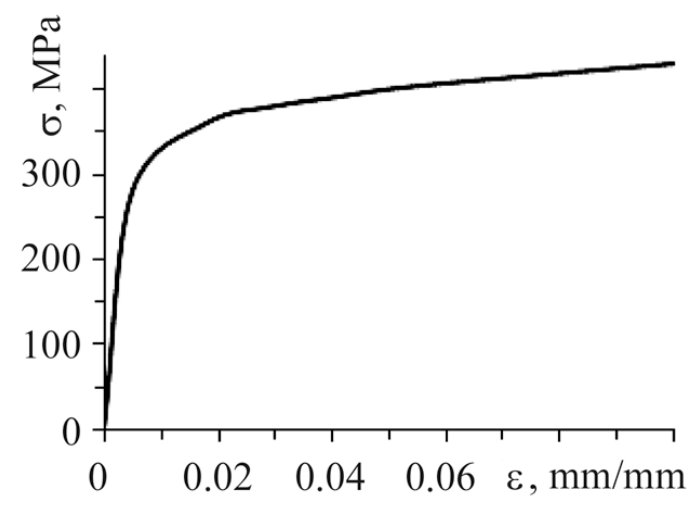

Fig. 2. Tensile stress-strain diagram of D16chT aluminum alloy.

The aim of the present work is to simulate the process of plastic deformation of a tool made of SMA by the FEM and compute residual stresses formed in the vicinity of a functional hole.

\section{Procedure of Investigations}

In the present work, the residual compressive stresses in the vicinity of a hole are determined by using the FEM and the method of cold strengthening of holes with the help of a tool made of SMA. The numerical simulations were carried out in the ANSYS Workbench software environment for materials with unilateral shape memory [21].

Consider a plate in an $X Y Z$ coordinate system. Assume that no motion is possible at the point $A$ along the $Z$-axis (Fig. 1a). We constructed 3D finite-element geometric models of a plate containing a hole (Fig. 1b) and a working tool made of SMA (Fig. 1c).

We study a square plate $t=6 \mathrm{~mm}$ in thickness and $40 \times 40 \mathrm{~mm}$ in cross-sectional sizes made of D16chT aluminum alloy and containing a functional hole whose diameter can be equal to $d=8 ; 10$, or $12 \mathrm{~mm}$ (Fig. 1b). The working tool made of SMA has the form of a cylinder of length $L=12 \mathrm{~mm}$ (Fig. 1c). The stress-strain diagram of the aluminum alloy under uniaxial tension is presented in Fig. 2. The mechanical characteristics of 


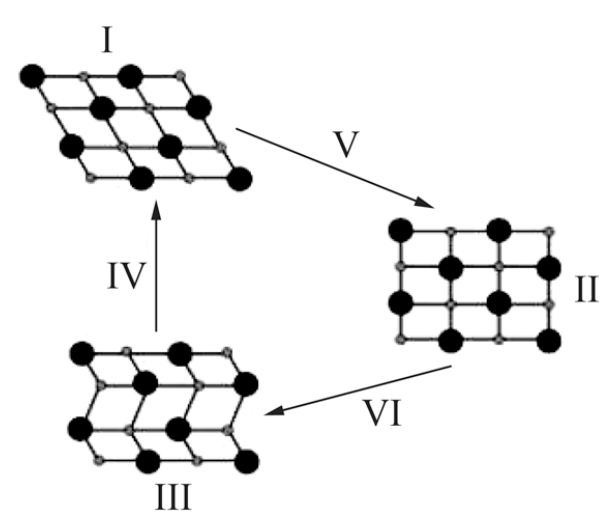

Fig. 3. Transformations of the crystal lattice in shape-memory alloys: (I) martensite in the phase without twinning; (II) austenite; (III) twin martensite; (IV) loading; (V) heating; (VI) cooling.

Table 1

Physicomechanical Characteristics of NiTi Alloy with the Shape-Memory Effect [23]

\begin{tabular}{c|c|c|c|c|c|c}
\hline \multirow{2}{*}{$\begin{array}{c}\text { Elasticity modulus, } \\
\text { MPa }\end{array}$} & \multirow{2}{*}{$\begin{array}{c}\text { Poisson's } \\
\text { ratio }\end{array}$} & \multicolumn{4}{|c}{$\begin{array}{c}\text { Temperatures } \\
\text { of transformations, }{ }^{\circ} \mathrm{C}\end{array}$} \\
\cline { 4 - 7 } & & \multicolumn{2}{|c}{ Martensite phases } & \multicolumn{2}{c}{ Austenite phases } \\
\hline$E_{a}$ & $E_{m}$ & $v$ & $M_{f}$ & $M_{s}$ & $A_{s}$ & $A_{f}$ \\
\hline 52700 & 45000 & 0.33 & -96 & -69 & -60.5 & -38.7 \\
\hline
\end{tabular}

D16chT alloy at $20^{\circ} \mathrm{C}$ are as follows: $\sigma_{\text {uts }}=300 \mathrm{MPa}$ and the ultimate strength $\sigma_{0.2}=430 \mathrm{MPa}$. The physicomechanical characteristics of the tool material are presented in Table 1 [23].

The martensite phase appears at lower temperatures, and the crystallographic lattice changes twice (Fig. 3), namely, twinning in the cold state is followed by the reorientation under loading with preservation of deformation in this phase after unloading. The elevation of temperature up to $A_{f}$ leads to the austenite transformation and returns the material into the initial nondeformed state.

In Table 2, we present the diameters of the hole made in the plate of D16chT alloy and of the tool made of NiTi alloy prior to, $D_{0}$, and after, $D_{1}$, deformation in the martensite phase. For the numerical analyses, we chose working tools with shape memory in the form of continuous cylinders with diameters $D_{0}=8,10$, and $12 \mathrm{~mm}$ larger than the initial diameter of the hole in the plate $d_{0}$. The cylinder was deformed by uniaxial tension down to a diameter $D_{1}<d_{0}$ and placed into the hole. In the course of heating up to the temperature $A_{f}$; the SMA passes into the austenite phase, expands in the hole of the plate up to the diameter $d_{0}$ and, hence, creates stresses in a vicinity of the hole. After cooling down to the temperature $M_{f}$, the tool was removed from the hole. This procedure leads to the formation of compressive residual stresses in the vicinity of the hole. The degree of expansion of the hole can be found by using the formula

$$
i=\frac{d_{1}-d_{0}}{d_{0}} \cdot 100 \%
$$


Table 2

Geometric Sizes of the Plate and the Tool Made of SMA

\begin{tabular}{|c|c|c|c|c|c|}
\hline $\begin{array}{l}\text { Plate size, } \\
\qquad a \times b\end{array}$ & $\begin{array}{l}\text { Initial diameter of } \\
\text { the tool } D_{0}\end{array}$ & $\begin{array}{c}\text { Diameter } \\
\text { of the tool after } \\
\text { deformation } D_{1}\end{array}$ & $\begin{array}{l}\text { Initial diameter } \\
\text { of the hole } d_{0}\end{array}$ & $\begin{array}{c}\text { Diameter } \\
\text { of the hole after } \\
\text { strengthening } d_{1}\end{array}$ & $\begin{array}{c}\text { Degree } \\
\text { of cold expansion } \\
\end{array}$ \\
\hline \multicolumn{5}{|c|}{$\mathrm{mm}$} & \\
\hline \multirow{6}{*}{$40 \times 40$} & \multirow{2}{*}{8} & 7.736 & 7.76 & 7.95 & 2.4 \\
\hline & & 7.736 & 7.84 & 7.96 & 1.5 \\
\hline & \multirow{2}{*}{10} & 9.67 & 9.70 & 9.94 & 2.4 \\
\hline & & 9.67 & 9.80 & 9.95 & 1.5 \\
\hline & \multirow{2}{*}{12} & 11.604 & 11.64 & 11.93 & 2.4 \\
\hline & & 11.604 & 11.76 & 11.94 & 1.5 \\
\hline
\end{tabular}

For the discretization of the model, we used a 20-node 3D finite element (FE; SOLID186). To increase the accuracy of calculations by the FEM, the plate was discretized by tetrahedra with sides of $2 \mathrm{~mm}$ (see Fig. 1b).

Moreover, in the vicinity of the hole, we used tetrahedra with sides of $0.5 \mathrm{~mm}$. The tool was discretized with the help of 20-node FE with sides of $1 \mathrm{~mm}$ (see Fig. 1c).

The process of plastic deformation of the hole was modeled in five stages. The working tool is first deformed by tension at a temperature $M_{f}=-96^{\circ} \mathrm{C}$ (I); then it is unloaded and placed into the hole made in the plate at a temperature $M_{f}=-96^{\circ} \mathrm{C}$ (II). Then the tool placed into the hole is heated up to a temperature higher than $A_{f}=-15^{\circ} \mathrm{C}$ (III). Finally, the tool is deformed by tension inside the hole (IV) at a temperature $M_{f}=-96^{\circ} \mathrm{C}$ in order to be able to pull it out of the hole $(\mathrm{V})$.

\section{Results of Investigations}

We plotted the distributions of normal residual stresses $\sigma_{y}$ along the $X$-axis in the vicinity of the functional hole for the degrees of cold expansion $i=1.5$ and $2.4 \%$ (Figs. $4 \mathrm{a}, \mathrm{b}$ ) and compared them with the results of FEM evaluation of residual stresses for the plates $60 \mathrm{~mm}$ in width with holes of the corresponding diameters [13] for the degrees of cold expansion $i=2$ and 3\%. We present the plots of residual stresses in the vicinity of the hole for the diameters equal to $8 \mathrm{~mm}$ (Figs. $4 \mathrm{a}, \mathrm{b}$ ) and 10 or $12 \mathrm{~mm}$ (Figs. 4c, d) both in the middle section of the plate $Z=t / 2$ (Figs. 4a, c) and on its surface $Z=t$ (Figs. 4b, d).

The dependences of the maximum compressive residual stresses (on the surface of the hole) on the diameter of the hole $d=8,10$, and $12 \mathrm{~mm}$ and the degree of cold expansion $i=2.4$ and $1.5 \%$ for $Z=t / 2$ are shown in Fig. 5a. For the investigated degrees of cold expansion, the lowest residual stresses are formed near the hole $10 \mathrm{~mm}$ in diameter, while the highest stresses are detected in the vicinities of the holes 8 and $12 \mathrm{~mm}$ in diameter. The larger the diameter of the hole, the smaller the difference between the residual stresses on its surface in the middle section of the plate (across its thickness) for the relative expansions of the hole equal to 1.5 and $2.4 \%$. For the hole with a diameter of $12 \mathrm{~mm}$, the residual normal stresses (for $x=d / 2$ ) coincide for both 

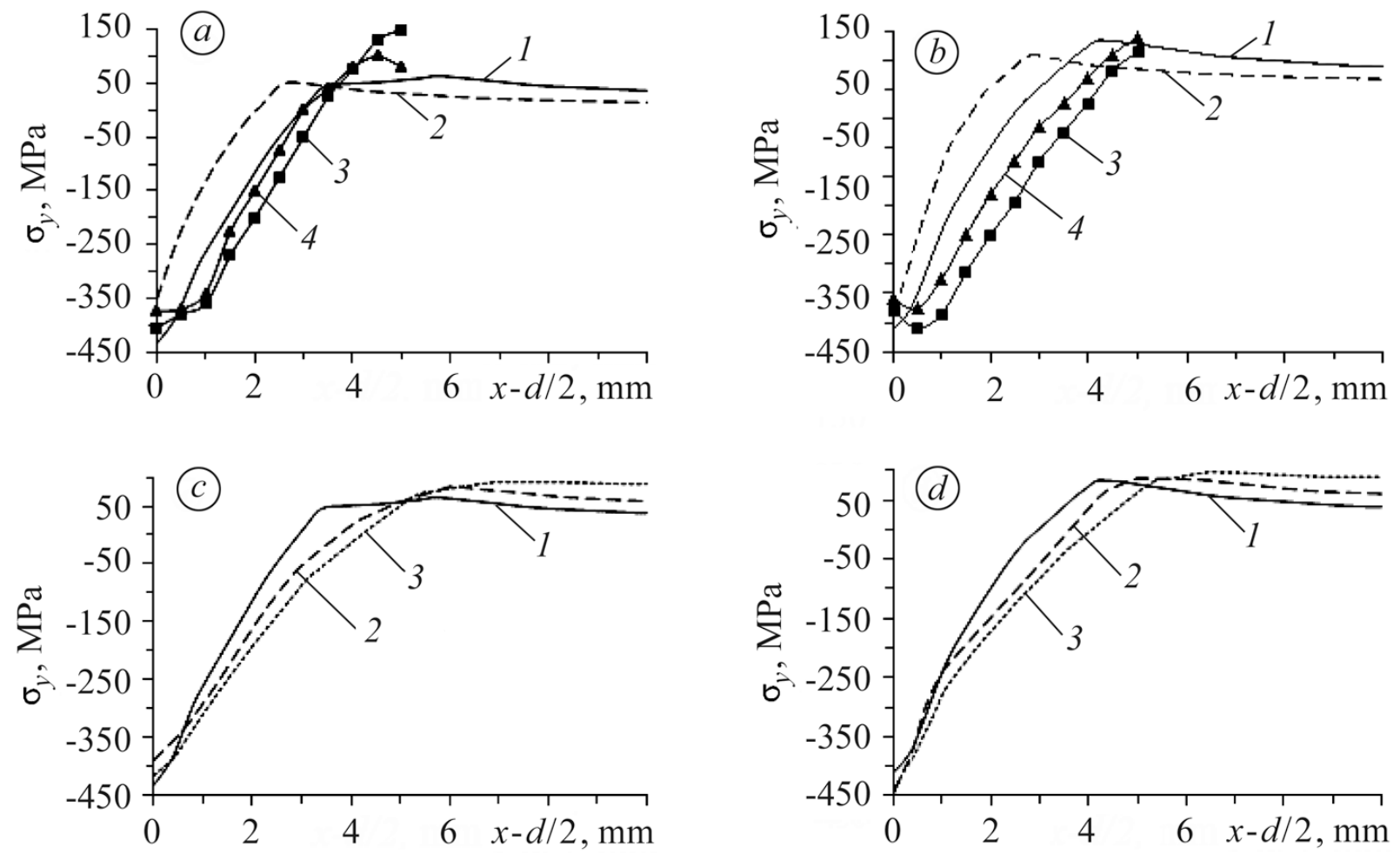

Fig. 4. Distributions of normal residual stresses along the $X$-axis in the vicinity of functional holes with diameters equal to $8 \mathrm{~mm}((\mathrm{a}, \mathrm{b})$ : (1) $2.4 \%$; (2) $1.5 \%$; (3) $3 \%$ [13]; (4) $2 \%$ [13]) and to 10 or $12 \mathrm{~mm} \mathrm{(c,d)} \mathrm{for} Z=t / 2$ (a, c) and $Z=t$ (b, d) for the degree of cold expansion $i=2.4 \%$ ((c, d): for the diameter of (1) $8 \mathrm{~mm}$; (2) $10 \mathrm{~mm}$; (3) $12 \mathrm{~mm}$ ).
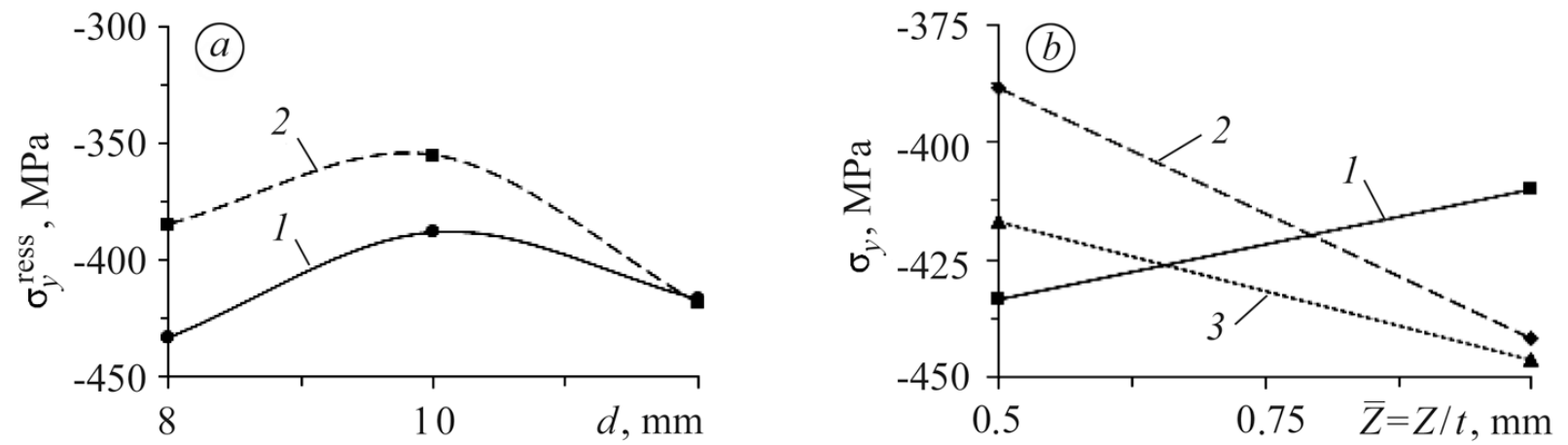

Fig. 5. Dependences of the maximum residual compressive stresses on the diameter of the hole for $Z=t / 2 \quad$ [(a): (1) $2.4 \%$; (2) $1.5 \%$ ] and their distribution across the thickness of the plate $\bar{Z}=Z / t \quad$ (b) with $d=8$ (1); 10 (2), and $12 \mathrm{~mm}$ (3) for the degree of cold expansion $i=2.4 \%$.

degrees of relative expansion. In Fig. 5b, we show the distributions of residual stresses on the surface of the hole $(x=d / 2)$ across the thickness of the plate for the degree of cold expansion $i=2.4 \%$. For the holes 10 and $12 \mathrm{~mm}$ in diameter, the maximum compressive stresses near the hole are formed on the surface of the plate and, for the hole $8 \mathrm{~mm}$ in diameter and the same degree of cold expansion, the maximum stresses are formed in the middle of the plate. The indicated inversion can be explained by different ratios of the diameters of the hole to the thickness of the plate. 


\section{CONCLUSIONS}

By the finite-element method, we simulated the process of cold plastic deformation of a hole in the plate with the help of a working tool made of SMA and plotted the distributions of residual stresses in the vicinity of the hole for various diameters and degrees of cold expansion. The procedure of mandrelling is based on the ability of SMA to exhibit a unilateral shape-memory effect. The maximum normal compressive stresses are formed on the plate surface in vicinities of the holes 10 and $12 \mathrm{~mm}$ in diameter for the same degrees of cold expansion and in the middle of the plate for the hole with $\varnothing 8 \mathrm{~mm}$. The indicated inversion can be explained by different ratios of diameters of the hole to the plate thickness. For the degrees of cold expansion $i=1.5$ and $2.4 \%$, the lowest residual compressive stresses in the middle (across the thickness) section of the plate $(Z=t / 2)$ appear on the surface $(x=d / 2)$ of the hole $10 \mathrm{~mm}$ in diameter. At the same time, the highest stresses are formed on the surfaces of the holes with diameters of 8 and $12 \mathrm{~mm}$. The distribution of residual stresses in the vicinity of the hole obtained for the diameter of the tool $d=8 \mathrm{~mm}$ is in satisfactory agreement with the earlier obtained results of FEM simulations of the process of mandrelling of the holes in aluminum plates $60 \mathrm{~mm}$ in width for the relative expansions of the hole $i=2$ and $2.4 \%$.

\section{REFERENCES}

1. V. Giurgiutiu and A. Zagrai, "The use of smart materials technologies in radiation environment and nuclear industry," Proc. SPIE, 3985, 855-866 (2000).

2. M. H. Wu and L. McD. Schetky, "Industrial applications for shape memory alloys," in: Proc. of the Internat. Conf. on Shape Memory and Superelastic Technologies, ASM International, Materials Park (2000), pp. 171-182.

3. D. Tarniţă, D. Tarniţă, N. Bîzdoacă, and V. M. Mîndrilă, "Properties and medical applications of shape memory alloys," Rom. J. Morphol. Embryol., 50, No. 1, 15-21 (2009).

4. V. P. Iasnii, H. M. Nykyforchyn, O. T. Tsyrul'nyk, and O. Z. Student, "Specific features of deformation of the nitinol alloy after electrolytic hydrogenation," Fiz.-Khim. Mekh.Mater., 54, No. 4, 124-130 (2018); English translation: Mater. Sci., 54, No. 3, 582-588 (2019).

5. V.P. Iasnii, O.Z. Student, and H. M. Nykyforchyn, "Influence of hydrogenation on the character of fracture of nitinol alloy in tension," Fiz.-Khim.Mekh. Mater., 55, No. 3, 80-85 (2019); English translation: Mater. Sci., 55, No. 3, 386-391 (2019).

6. V. P. Iasnii, H. M. Nykyforchyn, O. Z. Student, and L. M. Svirska, "Fractographic features of the fatigue fracture of nitinol alloy," Fiz.-Khim. Mekh.Mater., 55, No. 5, 148-153 (2019); English translation: Mater. Sci., 55, No. 5, 774-779 (2020).

7. Y, Zhang, M. E. Fitzpatrick, and L. Edwards, "Analysis of the residual stress around a cold-expanded fastener hole in a finite plate," Strain, 41, No. 2, 59-70 (2005).

8. Y, Zhang, M. E. Fitzpatrick, and L. Edwards, "Measurement of the residual stresses around a cold expanded hole in an EN8 steel plate using the contour method," Mater. Sci. Forum Trans. Tech. Publ., 404, 527-534 (2002).

9. B. Kawdi and Dr. N. Shanmukh, "Cold hole expansion process for stress analysis and evaluation of fatigue properties," J. Mech. Civ. Eng., 21-27 (2009).

10. P. Yasniy, S. Glado, and V. Iasnii, "Lifetime of aircraft alloy plates with cold expanded holes," Int. J. Fatigue, 104, 112-119 (2017).

11. B. Nadri, L. Edwards, M. Fitzpatrick, and A. Lodini, "Measurement of residual stresses following overloading of cold expanded holes using the X-ray diffraction technique and finite element method," J. Neutron Res., 12, Nos. 1-3, 1-11 (2004).

12. V. Lacarac, D. Smith, and M. Pavier, "The effect of cold expansion on fatigue crack growth from open holes at room and high temperature," Int. J. Fatigue, 23, 161-170 (2001).

13. P. V. Yasnii, S. V. Hlad'o, V. V. Skochylyas, and O. I. Semenets, "Formation of residual stresses in plates with functional holes after mandrelling," Fiz.-Khim. Mekh. Mater., 50, No. 6, 95-98 (2014); English translation: Mater. Sci., 50, No. 6, 877-881 (2015).

14. H. D. Gopalakrishna, H. N. Narasimha Murthy, and M. Krishna, "Cold expansion of holes and resulting fatigue life enhancement and residual stresses in Al 2024 T3 alloy - An experimental study," Eng. Fail. Anal., 17, No. 2, 361-368 (2010).

15. M. Elajrami, H. Melouki, and F. B. Boukhoulda, "Effect of double cold expansion on the fatigue life of rivet hole," Int. J. Mining, Metall. Mech. Eng., 1, No. 2, 111-113 (2013).

16. T. Yordan and G. Duncheva, Device and Tool for Cold Expansion of Fastener Holes, Patent USA No. 8915114. B23P9/025 B2, Publ. 12.23.2014. 
17. S. Pasta and G. V. Mariotti, "Effect of residual stresses and their redistribution on the fatigue crack growth in cold-worked holes," in: Proc. of the Internat. Conf. "Crack Paths" (2009), pp. 895-902.

18. J. R. Kennedy and D. J. Larson, Jr., Method of Cold Working Holes Using a Shape Memory Alloy Tool, Patent USA No. 5265456A. B23P9/02, Publ. on 30.11.1993.

19. P. V. Yasnii, O. V. Dyvdyk, and V. P. Iasnii, A Tool Made of Shape-Memory Alloy and Intended for Strengthening of Holes in Plates [in Ukrainian], Patent of Ukraine No. 132422, MPK V24V 39/00, Publ. on 25.02.2019, Byul. No. 4.

20. K. M. Armattoe, C. Bouby, M. Haboussi, and T. Ben, "Modeling of latent heat effects on phase transformation in shape memory alloy thin structures," Int. J. Solids Struct., 88-89, 293-295 (2016).

21. K. Divringi and C. Özcan, Advanced Shape Memory Alloy Material Models for ANSYS [Electronic Resource], Ozen Eng., Sunnyvale, CA (2009), 94085 , No. 408.

22. F. Auricchio and L. Petrini, "Improvements and algorithmical considerations on a recent three-dimensional model describing stressinduced solid phase transformations," Int. J. Numer. Meth. Eng., 55, No. 11, 1255-1284 (2002).

23. V. Iasnii and R. Junga, "Phase Transformations and mechanical properties of the nitinol alloy with shape memory," Fiz.-Khim. Mekh. Mater., 54, No. 3, 107-111 (2018); English translation: Mater. Sci., 54, No. 3, 406-411 (2018). 